\title{
ANALISIS NILAI SOSIOLOGIS \\ SASTRA DALAM CERITA RAKYAT SI BAROAR \\ MANDAILING SUMATERA UTARA
}

\author{
Sulaiman Siregar \\ 8166191016
}

\section{Pendidikan Bahasa dan Sastra Indonesia PPs Universitas Negeri Medan}

\begin{abstract}
Abstrak. Penelitian ini bertujuan untuk mengetahui: (1) Unsur intrinsik dalam Cerita Rakyat Si Baroar, (2) kerelevanan cerita Si Baroar dengan nilai - nilai sosial yang hidup di tengah masyarakat Mandailing di Desa Panyabungan Tonga saat ini (3) dan kejadian - kejadian dalam cerita yang berhubungan dengan fakta - fakta sosial yang ada dalam masyarakat Mandailing di Desa Panyabungan Tonga. Adapun pendekatan yang digunakan yaitu pendekatan sosiologis sastra dan menggunakan teknik penelitian deskriptif kualitatif. Hasil penelitian berupa (1) unsur intrinsik yang meliputi, tema yang terkandung di dalamnya yaitu saktinya seorang anak setelah mengalami berbagai gejolak kehidupan. Alur dalam cerita Si Baroar ini merupakan alur campuran. Tokoh utama adalah Si Baroar, tokoh tambahan yaitu Sutan Pulungan, Si Sauwa, Sri Mayapada, dan Hulubalang. Latar yang dipakai dalam cerita ini adalah latar tempat, latar waktu, dan latar suasana. Sementara sudut pandangnya adalah menggunakan orang ketiga serba tahu. Dan yang terakhir gaya bahasa yang digunakan antara lain mengunakan majas hiperbola dan personifikasi. (2) Dalam cerita rakyat Si Baroar terdapat nilai sosiologis masyarakat, baik itu secara material, vital dan spiritual (kebenaran, kebaikan, keindahan dan religi) dalam masyarakat Mandailing. (3) Masyarakat mandailing masih sangat mempercayai cerita Si Baroar, cerita Sibaroar ada yang relevan dan ada yang tidak relevan terhadap masyarakat Mandailing. Nilai materil dan nilai spiritual yang masih relevan, karena masyarakat sudah mengalami perubahan dalam pola berfikir.
\end{abstract}

Kata Kunci : nilai sosiologis, cerita rakyat, kerelevanan

\section{PENDAHULUAN}

Sastra

merupakan

pencerminan masyarakat. Melalui karya sastra, seorang pengarang sendiri ikut berada di dalamnya. Karya sastra menerima pengaruh dari masyarakat dan sekaligus mampu memberi pengaruh terhadap masyarakat. Bahkan sering kali masyarakat sangat menentukan nilai karya sastra yang hidup disuatu zaman, sementara sastrawan sendiri adalah anggota masyarakat yang terikat status sosial tertentu dan tidak dapat mengelak dari adanya pengaruh yang diterimanya 
dari lingkungan yang membesarkan sekaligus membentuknya.

Karya sastra itu sendiri bersifat dinamis berjalan dengan perkembangan masyarakat karena sastra itu hasil ciptaan seseorang yang merupakan bagian dari masyarakat. Di dalam masyarakat seorang individu menjalani berbagai macam kejadian yang ia alami. Dari kejadian yang dialami pada dunia nyata itulah sebagai dasar ide dalam penulisan karya sastra.

Keberagaman budaya disejajarkan oleh Bhinneka Tunggal Ika sebagai pemersatu bangsa Indonesia. Selain hal di atas, budaya dapat diketahui juga dari cerita-cerita yang sering kita baca atau kita dengar. Cerita tersebut sangat bersangkutan dengan sastra. Sastra memiliki nilai dan kekhasan tersendiri dalam perkembangan sastra.

Sastra terbagi menjadi dua bagian yaitu sastra lisan dan sastra tulisan. Sastra lisan atau kesusastraan lisan adalah kesusatraan yang mencakup ekspresi kesusastraan warga suatu kebudayaan yang disebarkan dan diturun-temurunkan secara lisan (dari mulut ke telinga) termasuk cerita Si Baroar. Penyebaran cerita Si Baroar secara lisan dan hanya berdasarkan daya ingat penuturnya. Sehingga tidak mustahil sangat mudah mengalami perubahan dan penyimpangan dari bentuknya yang asli.
Selain itu, orang tua yang menguasai sastra lisan $\mathrm{Si}$ Baroar jumlahnya semakin kecil. Keadaan ini mempercepat punahnya sastra lisan yang asli dan terjadilah kesalahan penafsiran pada kalangan masyarakat era baru terhadap sastra lisan $\mathrm{Si}$ Baroar yang berasal dari Mandailing. Sastra lisan juga merupakan nilai-nilai luhur yang harus dikembangkan misalnya mitos, legenda, dongeng, dan lain -lain.

Sastra tulisan adalah sastra yang timbul setelah manusia mengenal tulisan, di Indonesia mulai berlangsung setelah bangsa Indonesia berkenalan dengan kebudayaan asing, yakni kebudayaan Hindu, Islam, dan Barat (KBBI, 2005:1002). Sastra tulisan dalam penyampaiannya adalah melalui tulisan yang sudah dibukukan dan dibaca banyak orang. Sastra tulisan ini banyak yang berasal dari sastra lisan misalnya dongeng yang diceritakan dari seseorang kemudian diceritakan dan dibukukan oleh orang yang mendengarnya. Dengan segala kekurangan penulis mengangkat karya sastra tersebut berupa cerita rakyat yaitu Si Baroar yang berasal dari desa Panyabungan Tonga Mandailing, Sumatera Utara. Penulis tertarik meneliti cerita tersebut karena sepengatahuan penulis belum pernah ada yang mengkaji dan mengembangkannya. Karya sastra hadir sebagai wujud nyata imajinatif kreatif seorang sastrawan 
dengan proses yang berbeda antara pengarang yang satu dengan pengarang lain, terutama dalam penciptaan cerita fiksi. Proses tersebut bersifat individualis artinya cara yang digunakan oleh tiap-tiap pengarang dapat berbeda. Perbedaan itu meliputi beberapa hal diantaranya metode, munculnya proses kreatif, dan cara mengekspresikan apa yang ada dalam diri pengarang hingga bahasa penyampaian yang digunakan.

Dari pandangan di atas, maka dalam mengkaji suatu karya sastra dapat dihubungkan dengan sastra. Ilmu tersebut membahas karya sastra yang dihubungkan dengan masyarakat sehingga disebut sosiologi sastra. Sosiologi sastra juga dapat didefenisikan penelitian terhadap karya sastra dan keterlibatan struktur sosialnya (Ratna,2003:25). Dengan dua pengertian tersebut maka karya sastra dapat dihubungkan dengan masyarakat. Karya sastra adalah dunia miniatur karena sastra berfungsi sebagai pengekspresian kejadian-kejadian yang telah dikerangkakan dalam pola kreativitas dan imajinasi.

Melalui karya sastra sering diketahui keadaan, cuplikan-cuplikan kehidupan masyarakat, seperti dialami, dicermati, ditangkap, dan direka oleh pengarang. Sastra dan masyarakat erat kaitannya karena pada dasarnya keberadaan sastra sering bermula dari persoalan dan permasalahan pada manusia serta lingkungannya. Kemudian, dengan adanya imajinasi yang tinggi seorang pengarang tinggal menuangkan masalahmasalah di sekitarnya menjadi sebuah karya sastra.

Salah satu karya sastra yang dapat dikaji dalam pemahaman sastra, yaitu cerita rakyat. Salah satu ciri teks sastra yang multiinterpretasi membuat tanggapan pembaca terhadap satu cerita rakyat yang sama tentu akan berbeda-beda sesuai dengan tingkat pemahaman dan daya imajinasi pembaca, (Riris K. TohaSarumpaet,2002:35).

Hal tersebut membuat pemahaman sastra di masyarakat menjadi lebih menarik, terlebih jika masyarakat mampu menafsirkan cerita yang ada didalam masyarakat itu sendiri. Pemahaman apresiasi sastra merupakan rangka memperkenalkan karya sastra kepada masyarakat. Hal tersebut bertujuan agar masyarakat memiliki kemampuan menghayati, memahami, dan menikmati serta menilai karya sastra yang dibacanya. Setelah usaha itu dilakukan masyarakat diharapkan dapat mengambil manfaat dari karya yang dibacanya. Masyarakat diharapkan akan meneladani sikap dan nilai-nilai kehidupan yang positif dari tokoh-tokoh yang ada di dalam karya satra itu. 
Salah satu cerita yang dapat ditemukan dalam suatu daerah ialah Cerita Rakyat Si Baroar yang berasal dari Mandailing Sumatera Utara. Cerita Rakyat Si Baroar berisikan tentang seorang anak yang sangat sakti. Dalam cerita Si Baroar ini mengisahkan seorang Raja yang bernama Sutan Pulungan yang bertindak semena - mena terhadap rakyatnya, salah satunya berupaya membunuh Si Baroar dengan alasan yang tidak wajar. Si Baroar adalah anak yang dipungut dari tengah hutan saat berburu rusa oleh raja Sutan Pulungan beserta pasukannya, kemudian ia diserahkan dan sekaligus di asuh seorang Inang Asuh bernama si Sauwa yang sama sekali belum punya anak di sebuah perkampungan di Panyabungan Tonga.

Ketika Si Baroar berusia enam tahun, di saat bersamaan anak dari raja Sutan Pulungan mempunyai kemiripan yang persis sama dengan si Baroar, orangorang sering keliru menyapa ketika bertemu dengan salah seorang dari kedua anak tersebut. Jika si Baroar berjalan-jalan sendirian, orang-orang yang bertemu dengannya selalu memberi hormat kepadanya dan menyapanya seperti menyapa putra Sutan Pulungan.

Tetapi sebaliknya, jika bertemu dengan putra Sutan Pulungan, mereka memperlakukannya seperti anak rakyat biasa. Dengan alasan ini, di saat itu Raja Sutan Pulungan merasa terhina atas kejadian tersebut, sehingga ia memutuskan untuk membunuh Si Baroar secara rahasia. Namun yang terjadi malah putra Sutan Pulungan yang terbunuh, disebabkan kekeliruan parahulubalang ketika membunuhnya.

Pentingnya mengkaji nilai sosial dalam cerita rakyat karena sesuai fungsi sastra adalah merangsang pembaca untuk mengenali, menghayati, menganalisis, dan merumuskan nilai-nilai kemanusiaan. Secara halus nilai-nilai itu menjadi terjaga dan berkembang dalam diri pembaca. Pada akhirnya nilai-nilai itu menjadi motivasi dan stabilitas kepribadian dan perilakunya, (Muhardi dan Hasanuddin, 1992:15). Cerita ini berisikan ajaran-ajaran budaya dan pesan-pesan moral yang berguna bagi penulis dan pembaca, juga terdapat nilainilai sosiologi seperti kekuasaan yang salah gunakan dan niat jahat yang dilakukan pada orang yang tak bersalah maka kita sendiri yang dapat musibah.

Dengan demikian karya sastra bukanlah suatu uraian-uraian kosong atau khayalan yang sifatnya sekedar menghibur pembaca saja, akan tetapi melalui karya sastra tersebut dihidupkan oleh pembaca agar lebih arif dan bijaksana dalam bertindak dan berfikir. Bila dilihat dari segi nilai-nilai yang terkandung di dalam Cerita Rakyat Si Baroar sangat menarik untuk dibahas dalam meningkatkan rasa persaudaraan dalam bermasyarakat. 
Karena itu, peneliti tertarik untuk membuat penelitian yang berjudul "Nilai Sosiologis Sastra Dalam Cerita Rakyat " $\mathrm{Si}$ Baroar" Mandailing Sumatera Utara".

\section{METODOLOGI PENELITIAN}

Metode yang dipergunakan dalam penelitian ini adalah metode penelitian deskriptif kualitatif. Metode deskriptif merupakan suatu cara untuk memecahkan permasalahan yang menjadi tujuan dalam penelitian ini dengan cara mendeskripsikan dan menggambarkan keadaan subjek atau objek penelitian berdasarkan fakta-fakta yang ditemukan di lokasi penelitian.

Metode deskriptif kualitatif akan menghasilkan pendeskripsian yang sangat mendalam karena ditajamkan dengan analisis kualitatif. Hal itu sangat memungkinkan meningkatnya kualitas teknis analisis data sehingga hasil penelitian pun semakin berkualitas. (Mahi, 2011:37).

Lokasi penelitian ini adalah Desa Panyabungan Tonga Mandailing, Sumatera Utara.. Peneliti mengambil lokasi penelitian di daerah Desa Panyabungan Tonga, karena daerah ini merupakan salah satu daerah yang mempunyai kepercayaan tentang adanya cerita Si Baroar. Selain itu, mayoritas masyarakat Desa Panyabungan Tonga telah fasih berbahasa Indonesia yang dapat menunjang berjalannya penelitian dalam hal berkomunikasi. Penelitian dilaksanakan pada bulan September 2015.

Mangacu pada pendapat di atas, maka instrumen pada penelitian ini adalah peneliti sendiri dibantu dengan alat perekam suara. Untuk memperoleh data yang sesuai dengan permasalahan penelitian, maka pengumpulan data yang digunakan adalah dengan cara wawancara. Peneliti mewawancarai narasumber seputar cerita $\mathrm{Si}$ Baroar dan merekam pendapat narasumber terhadap cerita tersebut. Kemudian peneliti membandingkan antara satu cerita dengan cerita yang lain guna mendapat perubahanperubahan yang terjadi dalam cerita $\mathrm{Si}$ Baroar yang dulu dengan yang sekarang.

Untuk memperoleh data yang akurat teknik triangulasi data dapat digunakan dalam penelitian ini, karena teknik ini menggabungkan tiga aspek penelitian yaitu observasi, wawancara dan dokumentasi. Mengingat data yang akan dicari adalah tanggapan yang berupa persepsi dari masyarakat Desa Panyabungan Tonga mengenai cerita $\mathrm{Si}$ Baroar.

Untuk mengelola data yang diperoleh dalam penelitian ini, dianalisis dengan menggunakan teknik deskriptif 
kualitatif yaitu merupakan teknik pemecahan masalah yang diteliti dengan cara menggambarkan atau melukiskan keadaan objek atau subjek penelitian. Menurut Suryana (2007:10-12), langkahlangkah analisis data dalam penelitian kualitatif adalah reduksi data, display data, analisis data, mengambil kesimpulan dan verifikasi, meningkatkan keabsahan hasil, dan narasi hasil analisis.

\section{PEMBAHASAN}

Penelitian ini merupakan penelitian observasi lapangan dengan melibatkan beberapa masyarakat Desa Panyabungan Tonga untuk diminta memberi tanggapan atas pertanyaan mengenai Si Baroar untuk kemudian dianalisis dan dipaparkan secara deskriptif. Data yang diperoleh dalam penelitian ini adalah data masyarakat Desa Panyabungan Tonga, Mandailing Sumatera Utara terhadap nilai sosiologi cerita Si Baroar.

Adapun jumlah masyarakat Desa Merdeka yang menjadi informan dalam penelitian ini adalah berjumlah 10 orang, dengan klasifikasi usia tua (50 tahun keatas) yaitu Sayuddin Nasution (68), Khairuddin Batubara (69), H. Nauli Hasean Nasution(74), dan Ali Rachman Nasution S.H (52). Usia menengah (26-49 tahun) yaitu Rohima Nasution (35), Muhammad Fuad Nasution S.Sos (38), dan Saida Nasution (31).
Dan usia muda (15-25 tahun) yaitu Muhammad Siddik Nasution (23), Misbah Hasanah Lubis (22), Muhammad Fauzi (22).

Dengan alasan semua narasumber mengetahui kisah Si Baroar dan memang pernah terjadi, hingga dulu sampai sekarang masyarakat Panyabungan Tonga mewarisi cerita Si Baroar dari nenek moyang terdahulu, sehingga masyarakat penduduk setempat mengetahui bagaimana alur cerita tersebut.

Menurut responden golongan usia tua (50 tahun keatas) membenarkan cerita Si Baroar pada awalnya hanya rakyat biasa dan akhirnya menjadi raja yang sangat sakti disaat itu. Namun ketika ditanya mengenai fungsi $\mathrm{Si}$ Baroar untuk masa sekarang, tidak terdapat warisan kesaktian Si baroar terhadap keturunannya baik itu dalam kepemimpinannya maupun membangkitkan kembali kejayaan kerajaan Si Baroar yang hanya tinggal nama.

Responden golongan usia menengah (26-49 tahun) terhadap pertanyaan mengenai kebenaran cerita $\mathrm{Si}$ Baroar yang sangat sakti, hampir semua sepakat bahwa itu adalah benar adanya. Namun semua responden yang menyatakan bahwa Si Baroar sejak dahulu sangat sakti dan ada juga yang yang menyatakan orang yang beruntung. Namun ketika ditanya mengenai funngsi cerita $\mathrm{Si}$ 
baroar ditengah masyarakat saat ini, pernyataan responden hanyalah peninggalan bersejarah dan sewaktu-waktu kalau diadakan pesta suatu pernikahan.

Dapat dipahami bahwa golongan usia muda (15-25 tahun) tetap mengakui kebenaran cerita Si Baroar pada awalnya ia adalah orang yang sakti pada zamannya. Dan ketika ditanya untuk fungsi cerita Sibaroar saat ini, responden golongan usia muda memandang bahwa tidak jauh dengan pendapat sebelumnya, yaitu berupa peninggalan kerajaan. Sehingga tercatat sebagai bangunan bersejarah dan dalam bentuk lain dari cerita ini mewariskan adat istiadat.

\section{HASIL PENELITIAN}

\section{Unsur Intrinsik dalam Cerita Rakyat}

\section{Si Baroar}

Tema yang diangkat dari cerita ini adalah saktinya seorang anak setelah mengalami berbagai gejolak kehidupan. Dilihat dari tema yang diangkat, isi cerita ini menggambarkan tokoh utama yang sejak kecil di asuh seorang dayang ( $\mathrm{Si}$ Sauwa) pada kerajaan Sutan Pulungan hingga ia sukses menjadi seorang Raja. Tema ini menonjol ketika Si Baroar berusia lima tahun mempunyai kemiripan yang persis sama dengan anak Raja Sutan Pulungan, sehingga para rakyat terkadang salah memberi hormat diantara keduanya.
Alur dalam cerita Si Baroar ini merupakan alur campuran, karena kisah awal menceritakan masa lalu sejak ia kecil sampai saat ia diasuh dayang kerajaan yaitu Si Sauwa, dan berakhir pada kisah setelah ia menjadi seorang raja di Desa Panyabungan Tonga.

Pada cerita Si Baroar yang termasuk ke dalam tokoh utama yaitu, tokoh Si Baroar. Tokoh Si Baroar ini yang mengalami banyak konflik di dalamnya, karena tokoh $\mathrm{Si}$ Baroar sebagai pusat dalam cerita rakyat ini. Namun, terdapat pula tokoh tambahan yang membangun konflik tokoh Si Baroar, diantaranya: Si Sauwa, Raja Sutan Pulungan, Sri Mayapada dan Hulubalang Kerajaan. Latar dalam cerita ini terbagi menjadi empat, diantaranya: latar tempat, latar waktu, dan latar suasana. Dalam cerita $\mathrm{Si}$ Baroar ini menggunakan sudut pandang orang ketiga serba tahu, karena dalam cerita ini pun tampak diawali pada bagian pertama dengan sudut pandang orang ketiga serba tahu. Dari sudut pandang orang ketiga serba tahu ini, mengetahui segala hal yang terjadi pada setiap tokoh yang terdapat dalam cerita, baik dari segi peristiwa, perasaan, pikiran, maupun pandangan setiap tokoh terhadap berbagai hal. Gaya bahasa yang digunakan antara lain mengunakan majas hiperbola, personifikasi, dan klimaks. 


\section{Nilai dalam cerita "Sibaroar" masih relevan dengan nilai - nilai sosial yang hidup di tengah masyarakat Mandailing di Desa Panyabungan Tonga saat ini.}

Data yang dianalisis peneliti adalah kalimat atau paragraf yang mengandung gambaran nilai - nilai sosiologis dalam cerita. Nilai sosiologi cerita terdapat tiga bagian di antaranya (1) nilai materil yaitu dalam cerita Si Baroar terdapat kebutuhan pangan seperti makanan dan pakaian, (2) nilai vital adalah pendukung dari nilai materil. Agar proses kerja lebih cepat dan mudah. Nilai vital yang terkandung dalam cerita Sibaroar adalah transportasi, transaksi jual beli, dan sebagainya (3) nilai spiritual yaitu segala sesuatu yang berguna bagi unsur rohani apabila memiliki daya guna, memiliki asas guna bagi rohani manusia. Nilai yang terdapat dalam cerita Sibaroar ini yaitu, nilai kebenaran, nilai keindahan, nilai kebaikan, dan nilai religious.

\section{Kejadian-kejadian dalam cerita $\mathrm{Si}$} Baroar masih berhubungan dengan fakta-fakta sosial yang ada dalam masyarakat Mandailing di Desa Panyabungan Tonga.

Fakta - fakta sosial yang terdapat dalam cerita $\mathrm{Si}$ Baroar pada umumnya masih berlaku pada pola kehidupan masyarakat Desa Panyabungan Tonga deawsa ini. Dalam cerita $\mathrm{Si}$ Baroar mengisahkan bila adanya suatu pesta semua ikut gotong royong mendirikan atau membangun Sopo Godang sekaligus diadakan horja bolon (pesta besar) dengan memotong kerbau. Dan ini masih diberlakukan hingga sekarang, yaitu memotong kerbau dalam suatu pesta misalkan pemberian marga dan pesta pernikahan. Maka adat ini diberlakukan bagi yang masih punya silsilah keturunan raja $\mathrm{Si}$ Baroar tersebut terkecuali masyarakat awam atau masyarakat biasa. Boleh saja masyarakat biasa atau masyarakat luar mengadakan adat tersebut akan tetapi bila ada kesanggupan untuk membiayai proses pesta yang mau dilaksanakan.

Masyarakat Mandailing masih menjunjung tinggi nilai budaya yang diwarisi keturunan Raja Si Baroar. Tenggang rasa, saling tolong menolong dan persaudaraan masih kuat misalnya dalam suatu acara besar seperti acara pernikahan ataupun acara lainnya. Hingga sekarang nilai budaya nilai budaya tersebut masih dipelihara dan dijaga baik oleh masyarakat Mandailiing.

\section{SIMPULAN}

1) Peneliti menganalisis unsur intrinsik yang meliputi, tema yang terkandung di dalamnya yaitu saktinya seorang 
anak setelah mengalami berbagai gejolak kehidupan. Alur dalam cerita $S i$ Baroar ini merupakan alur campuran. Tokoh utama adalah $\mathrm{Si}$ Baroar, tokoh tambahan yaitu Sutan Pulungan, Si Sauwa, Sri Mayapada, dan Hulubalang. Latar yang dipakai dalam cerita ini adalah latar tempat, latar waktu, dan latar suasana. Sementara sudut pandangnya adalah menggunakan orang ketiga serba tahu. Dan yang terakhir gaya bahasa yang digunakan antara lain mengunakan majas hiperbola, personifikasi, dan klimaks.

2) Dalam cerita rakyat Si Baroar terdapat nilai sosiologis masyarakat, baik itu secara material dan spiritual (kebenaran, kebaikan, keindahan dan religi) dalam masyarakat Mandailing. Sedangkan nilai vital tidak ditemui dalam cerita Si Baroar.

3) Cerita Si Baroar ada yang relevan dan ada yang tidak relevan terhadap masyarakat Mandailing. Nilai materil dan nilai spiritual yang masih relevan.karena masyarakat sudah mengalami perubahan dalam pola berfikir. Namun, masyarakat mandailing masih sangat mempercayai cerita Si Baroar, nilai-nilai sosiologi yang terdapat didalamnya tidak terlepas dari pola kehidupan yang semakin maju.

\section{DAFTAR PUSTAKA}

Abdullah, Imran. T. 1991. Resepsi Sastra: Teori dan Penerapannya. Dalam Jurnal Online Budaya, Sastra, dan Bahasa Fakultas Ilmu Budaya, Universitas Gadjah Mada. Vol. 1, No. 2

Arikunto, Suharsimi. 2010. Prosedur Penelitian Suatu Pendekatan Praktik. Jakarta : Rineka Cipta.

Danandjaja, James. 1984. Folklore Indonesian: Ilmu gosip, Dongeng, dan lain-lain. Jakarta: Grafiti Pers.

Escapit Robert (Kata Pengantar: Supardi D. Darmono). 2005. Sosiologi Sastra. Jakarta. Yayasan Obor Jakarta.

Emzir \& Rohman, Saifur. 2015. Teori dan Pengajaran Sastra. Jakarta: Rajawali Pers.

Endraswara, Suwardi. 2012. Filsafat Sastra: Hakikat, Metodologi dan Teori. Yogyakarta: Layar Kata.

Hilal, Al. 2012. Persepsi Masyarakat Di Kelurahan Tanjung Batu Kabupaten Ogan Ilir Tentang Pendidikan. Dalam Jurnal Online Studi Sosiologi Fakultas Ilmu Sosial dan Ilmu Politik, Universitas Sriwijaya. Vol. 1, No. 2 
M. Hikmat, Mahi. Metode Penelitian: Dalam Perspektif Ilmu Komunikasi dan Sastra. Yogyakarta: Graha Ilmu.

Meleong, Lexy J. 2006. Metodologi Peneletian Kualitatif. Bandung: Remaja Rosdakarya.

Nurgiyantoro, Burhan. 1995. Teori Pengkajian Fiksi. Yogyakarta: Gajah Mada University Press.

Pradopo, Rahmat Joko. Prinsip - Prinsip Kritik Sastra. Yogyakarta: Gajah Mada University Press.

Purba, Antilan.2001. Pengantar Ilmu Sastra. Medan: Usu Press.

Ratna, Nyoman Kutha. 2011. Antropologi Sastra. Yogyakarta: Pustaka Belajar.

Ratna, Nyoman Kuta. 2003. Paradigma Sosiologi Sastra. Yogyakarta. Pustaka Pelajar.

Sukatman. 2009. Butir - Butir Tradisi Lisan Indonesia Pengantar Teori dan Pembelajarannya. Yogayakarta: LaksBang.

Siti Aida Azis. 2009. http://kajiansastra.blogspot.com//0 4/sosiologi-sastra-sebagaipendekatan.html.
Sugiyono. 2011. Metode Penelitian Kuantitatif, Kualitatif dan $R \& D$. Bandung: Penerbit Alfabeta.

Wijaya. 2010. http://wijayalabs.wordpress.com/so siologi-sastra.

Wellek, Rene \& Warren, Austin. 1989. Teori Kesusastraan. Jakarta: Gramedia.

Yudiono. 2007. Pengantar Sejarah Sastra Indonesia. Jakarta: Grasindo.

http://ceritarakyatnusantara.com/id/folklor e/149-si-baroar.

http://rahmatamsari.blogspot.com/2012/11 /profil-suku-mandailing.html.

https://wijayalabs.wordpress.com/2010/04/ 30/sosiologi-sastra. 